\title{
Lyme Disease in Military Personnel
}

\author{
Sqn Ldr R P Gregory \\ MRCP, RAF
}

Senior Registrar in Neurology

Neurology Dept, Princess Alexandra Hospital, Royal Air Force Wroughton, Swindon, SN4 OQJ

\section{Wg Cdr A D Green \\ FRCPath, RAF}

Royal Air Force Institute of Pathology and Tropical Medicine, Halton, Aylesbury, Bucks, HP22 5PG

\author{
Gp Capt R T G Merry \\ FRCP, RAF \\ Consultant Adviser in Neurology \\ Neurology Dept, Princess Alexandra Hospital, Royal Air Force Wroughton, Swindon, SN4 OQJ
}

SUMMARY: The tick responsible for Lyme disease is common in areas inhabited by deer. This should theoretically put military personnel at increased risk. A history of tick bite is uncommon and the characteristic skin rash often absent. Two examples of servicemen with neurological Lyme disease without cutaneous manifestations are discussed, and six other cases referred to the RAF Institute of Pathology and Tropical Medicine since 1987 briefly reviewed. Five of the cases contracted the disease in Germany and four were dependents. Lyme disease is under-recognised and under-reported, so that the scale of the problem cannot be determined. It is recommended that wooded areas inhabited by deer should not be frequented without adequate clothing, particularly in the early summer months when tick activity is at its greatest.

\section{Introduction}

Tick-borne lymphocytic meningoradiculitis or Lyme disease as it is now commonly called, has been recognised since 1922 (1). It is only since the discovery of the causative agent by Burgdorfer (2) that the full spectrum of the clinical syndrome has been realised. The tick responsible is common in areas inhabited by deer, and most frequently feeds between May and July (3), so that individuals who frequent forests and other wooded areas during this time are particularly vulnerable. This should theoretically put military personnel at increased risk.

Although the skin, joints and heart may be affected, it is the nervous system which is most commonly involved, particularly in Europe (3). Antigenic differences in the respective species of Borrelia Burgdorferi are known to exist and it has been suggested that they are responsible for the varied manifestations (4). When a tick bite is followed by the typical Erythema Chronicum Migrans (ECM) rash, and subsequent neurological symptoms follow, the diagnosis is straightforward. This unfortunately is not always the case. A history of tick bite is only present in $10 \%$ and a rash in $50 \%$ (5). It is with the remainder that the diagnosis may be missed if the specific serological test is not sought.

We report two cases of neuroborreliosis without dermatological features that have recently been presented to the RAF Neurological Unit, and briefly review those patients with positive Lyme disease serology recorded at the RAF laboratory between 1987 and September 1991.

\section{Case Reports \\ Case 1}

A 46 year old army officer presented in June 1990 wit a constant non-specific headache. Three weeks later he developed diplopia worst on right gaze. There was no relevant past medical history although he frequently sunbathed in the New Forest dressed only in swimming trunks. Examination confirmed a right sixth nerve paresis with no other abnormalities. One week later he developed painful dysathesia over the back of his head. The ophthalmaplegia was unchanged but he now had a partial right lower motor neurone facial weakness, and altered sensation in a right $\mathbf{C} 2$ distribution. Routine investigations revealed moderately abnormal liver function tests. Abdominal ultrasound, chest radiograph, and magnetic resonance brain scans were normal. His CSF contained 322 white cells with normal morphology, a raised protein of $0.9 \mathrm{~g} / \mathrm{l}$ and a normal sugar. There was evidence of local synthesis of oligoclonal immunoglobulins within the central nervous system. A liver biopsy was normal.

Over the next 2 weeks his sixth and seventh nerve paresis improved. He then developed burning dysathesia over the left trunk and hand, which was hyperpathic from $\mathrm{C} 3$ to $\mathrm{T} 8$. He also had mild bilateral plexus weakness principally affecting the shoulder girdle muscles with areflexia of the arms. The legs were normal. At this stage he was given oral tetracycline $500 \mathrm{mg}$ four times daily, while confirmation of Lyme disease was awaited. His serum borrellia ELISA antibody titre was positive for IgM at $>1$ in 800 and IgG at 1 in 400. The CSF IgM 
and IgG titres were both $>1$ in 800 . The antibiotics were continued for 3 weeks, and this coincided with resolution of his symptoms and signs. His liver function tests returned to normal. He remained well on final review one year after the onset of his symptoms.

Case 2

In September 1991, a 40 year old RAF Mess Manager, presented in Germany with a 6 week history of painful dysathesiae that slowly spread over his trunk and onto the anterior aspect of his thighs. There was no relevent past history but he was Green Keeper of the station golf course, which frequently involved working in wooded areas inhabited by deer, often dressed only in shorts. Examination was normal apart from altered sensation from $\mathrm{T} 2$ to $\mathrm{L} 3$ bilaterally. Routine investigations were normal but his CSF protein was elevated at $1.1 \mathrm{~g} / \mathrm{l}$ with a normal sugar and no cells. There was local synthesis of oligoclonal immunoglobulins within the CNS which was specific for borrellia antigen. The antibody titres in serum and CSF were similar to Case 1 . There was some spontaneous resolution of his symptoms prior to the commencement of oral tetracycline, and this improved completely on 3 weeks therapy. He has remained well since.

In addition to these cases, 6 other patients have been diagnosed at the RAF laboratory since 1987 . Their details are given in the Table 1 . No cases have been seen at the Army or Royal Navy Laboratories.

\section{Table 1}

Lyme disease diagnosed in RAF Laboratories 1987-1991.

\begin{tabular}{|c|c|c|c|c|c|}
\hline Year & Age & Sex & Clinical Features & $\begin{array}{l}\text { Ser- } \\
\text { vice }\end{array}$ & $\begin{array}{l}\text { Ger- } \\
\text { many }\end{array}$ \\
\hline 1987 & 55 & $\mathbf{M}$ & $\begin{array}{l}\text { Bilateral facial } \\
\text { palsiesRAF }\end{array}$ & Yes & \\
\hline $\begin{array}{l}1988 \\
1989 \\
1990 \\
1991 \\
1991 \\
1991 \\
1991\end{array}$ & $\begin{array}{l}35 \\
28 \\
46 \\
13 \\
35 \\
47 \\
12\end{array}$ & $\begin{array}{l}\mathbf{F} \\
\mathbf{F} \\
\mathbf{M} \\
\mathbf{M} \\
\mathbf{M} \\
\mathbf{M} \\
\mathbf{M}\end{array}$ & $\begin{array}{l}\text { Facial palsy } \\
\text { Facial Palsy } \\
\text { Case } 1 \\
\text { Rash and arthralgia } \\
\text { Rash and lethargy } \\
\text { Case } 2 \\
\text { Headache and neck } \\
\text { stiffness }\end{array}$ & $\begin{array}{l}\text { Dep } \\
\text { Dep } \\
\text { Army } \\
\text { Dep } \\
\text { RAF } \\
\text { RAF } \\
\text { Dep }\end{array}$ & $\begin{array}{l}\text { Yes } \\
\text { Yes } \\
\text { No } \\
\text { No } \\
\text { No } \\
\text { Yes }\end{array}$ \\
\hline
\end{tabular}

\section{Discussion}

Although neither of the cases had the typical rash or history of tick bite, both had a painful migrating sensory disturbance occurring in a radicular distribution that is typical of acute neuroborreliosis. This characteristically presents as an acute monophasic meningoradiculopathy (Banwarths syndrome (7)) which may have additional signs of nerve root dysfunction as in case one. Facial nerve palsy was particularly common and may be the only manifestation of Lyme Disease (5). CNS manifestations can be seen such as myelopathy or hemiparesis, but none of our patients had these (6).
The CSF abnormalities in our patients were typical of neuroborreliosis although the lack of a pleocytosis in Case 2 is unusual and suggests that spontaneous resolu- $O$ tion of the inflammatory process may have already응 begun. Both had local synthesis of immunoglobulins inco their CSF with specific immunoblotting to lymes antigen $\Rightarrow$ in Case 2. This was not done in Case 1. The MRI scan in Case 1 was normal, although this may not always be the case (6). In the absence of CNS features the CT brain scan is invariably normal but the MRI commonly shows $\frac{\bar{\omega}}{\vec{D}}$ high signal white matter lesions. Although these may be을 similar in appearaence to those seen in multiple sclerosis, they frequently are more typical of small vasculitic $\overrightarrow{0}$ lesions. The abnormal liver function tests in case one was probably due to a mild hepatitis which is a well re- $\vec{\omega}$ cognised feature (3).

When the causative organism was discovered in 1983 (2), it became the vogue to treat patients with antibiotics. this was initially with intravenous penicillin and more $\frac{\dot{\omega}}{\omega}$ recently oral tetracycline (3). Both our patients werec given oral tetracycline, and although this coincided with오 resolution of the symptoms and signs, Case 2 may have already started to improve before treatment was given. $\omega$ Kruger and colleagues (8) recently compared the out come of patients diagnosed with Banwarths syndrorese $\vec{C}_{C}$ prior to 1983 and receiving no treatment, with a substequent group treated with antibiotics. CSF and serum ha्कd been saved in some of the historical patients and the diagnosis of Lyme disease could be serologically cofi- $\overrightarrow{0}$ firmed. There was no significant difference in either tofe course of the illness or the rate of CSF normalisation. The vast majority of patients in both groups madeoa complete recovery, with only a few having minor restdual disability. Patients treated with steroids did have faster resolution of pain but no significant improvement in the rate or degree of recovery. This suggests that the pathological process in acute neuroborreliosis may beō immune mediated.

Chronic neuroborreliosis has a different course and does appear to benefit from antibiotics. ECM, radicular pain, and facial palsy are rare and encephalitic features are more typical with decreased visual acuity, somnolence, and poor memory $(6,9)$. It is suggested that in these cases the $B$. Burdorferi persist in the CNS, and can only be influenced by treatment with antibiotics. The current recommendation for treatment in acute neuroborreliosis is 10-30 days of oral tetracycline in view? of the possible development of chronic illness (3). In theo North American disease, chronic arthritis is common. If ${ }^{3}$ neurological symptoms are severe or life threatening응 cardiac involvement is present then intravenous $>$ ceftrioxome should be given.

Since 1986, 105 cases have been reported to the Com- N municable Disease Surveillance Centre. The number $N$ seen at the RAF laboratory represents $7.6 \%$ of this fig-N ure. It is recognised that the true national figures are $\omega$ likely to be much higher, but it is likely that the RAF? 
figures are also an underestimate. Five of the cases however, probably contracted the disease in Germany. Lyme disease is under reported. It is currently not notifiable to the Proper Officer in England and Wales, but is notifiable within the Military on a Form Med 85 . There are instances whereby the diagnosis is made in civilian laboratories, and this coupled with a failure of notification may explain the apparent absence of disease in the Army and Royal Navy.

This infection has aroused considerable military interest, particularly within the United States, and combat clothing impregnated with Peripel is currently awaiting evaluation within the UK (Personnel Communication Mr K Chetwyn, Department of Entomology, Royal Army Medical College). Both cases presented here probably sustained their tick bites during recreational activities rather than as a direct consequence of service activities, and 4 of the 8 cases occurred in dependents. It is clearly unwise to frequent wooded areas inhabited by deer without long trousers and adequate footwear, particuarly in the early summer months when tick activity is at its greatest.

\section{REFERENCES}

1. Garin C, Bujadoux C. Paralysie per les tiques. $J$ Med Lyon 1922; $71 ; 767$.
2. Burgdorfer W, Barbour A G, Hayes S F, BebacG J L, GRunwaldt E, Davis J. Lyme disease - a tick- 3 borne spirochetosis Science 1982; 216: 1317-1319.

3. STEERE AC. Lyme disease. N Engl J Med 1989; 321: 586-605.

4. Barbour A G, Heilland R A, Howe T A. क्? Heterogeneity of major proteins in lyme disease $\Rightarrow$ borreliae. A molecular analysis of North America $\stackrel{0}{\rightarrow}$ and European isolates. $J$ Infect Dis 1985; 152: 47884.

5. Bateman D E, Lawton N F, White J E, GreENwood R J, Wight D J M. The neurological complications of Borrelia burgdorferi in the New Forse area of Hampshire. $J$ Neurol Neurosurg is Phychiatry 1988; 51: 699-703.

6. Kruger H, Helm E, Schuknecht B, Scholz S. Acute and chronic neuroborreliosis with and $\vec{\omega}$ without CNS involvement: a clinical, MRI, and $\stackrel{\sigma}{S}$ HLA study of 27 cases. $J$ Neurol 1991; 238: 271280.

7. Banwarth A. Chronische lymphozytare meningitis, entzundliche polyneuritis and rheumatismus. Arch Psychiatr Nervenkr 1941; 113: 284-376.

8. Kruger H, KOHLHEPP W, Konig S. Follow-up of antibiotically treated and untreated neurobor- $\mathrm{C}$

9. Logiosis. Acta Neurol Scand 1990; 82: 59-67. lyme disease. New Engl J Med 1990; 323; 1438 1444. 